\title{
Management of HeartWare left ventricular assist device thrombosis using intracavitary thrombolytics
}

\author{
Michael S. Kiernan, MD, ${ }^{a}$ Duc Thinh Pham, MD, ${ }^{\mathrm{b}}$ David DeNofrio, MD, ${ }^{\mathrm{a}}$ and Navin K. Kapur, MD, ${ }^{\mathrm{a}}$ \\ Boston, Mass
}

Left ventricular assist devices (LVADs) improve the survival and quality of life in patients with refractory heart failure compared with optimal medical therapy. Compared with pulsatile LVADs (p-LVADs), continuous-flow LVADs (cf-LVADs) demonstrate better survival with fewer device-related complications. ${ }^{1}$ However, the blood-contact surfaces of the p-LVADs promote the formation of a pseudointima that reduces thrombogenicity, whereas the impeller cf-LVADs do not generate a pseudointima and may have a higher rate of pump thrombosis. ${ }^{2}$ Experience with cf-LVAD thrombosis is limited. Although thrombolytic therapy has been described with axial-flow devices, ${ }^{3,4}$ there are no reports of thrombolysis with cf-LVADs.

The HeartWare system (HeartWare International Inc, Framingham, Mass) is a novel cf-LVAD that is implanted within the pericardial space and that generates up to 10 $\mathrm{L} / \mathrm{min}$ of flow. The HeartWare device is being investigated as a bridge to transplantation in a multicenter US clinical trial. The target international normalized ratio for the HeartWare LVAD is 2 to 3 . The risk of pump thrombosis associated with the HeartWare LVAD is unknown. We describe the management of a thrombotic HeartWare LVAD obstruction using intraventricular thrombolytics.

\section{CLINICAL SUMMARY}

A 57-year-old man with nonischemic cardiomyopathy underwent HeartWare LVAD implantation as a bridge to transplant. Five months later, the patient gained weight and dyspnea worsened. Admission LVAD speed was 2800 $\mathrm{rpm}$ with an estimated flow of $4.8 \mathrm{~L} / \mathrm{min}$. Mean blood pressure was $82 \mathrm{~mm} \mathrm{Hg}$. The patient's international normalized ratio was subtherapeutic at 1.4 because of medical

$\overline{\text { From the Divisions of Cardiology }}{ }^{\mathrm{a}}$ and Cardiothoracic Surgery, ${ }^{\mathrm{b}}$ Tufts Medical Center, Boston, Mass.

Disclosure: Drs Pham and DeNofrio are site principal investigators for the HeartWare clinical trial.

Received for publication Sept 15, 2010; revisions received Oct 22, 2010; accepted for publication Nov 14, 2010; available ahead of print Jan 31, 2011.

Address for reprints: Navin K. Kapur, MD, Tufts Medical Center, Cardiology, 800 Washington Street, Box 80, Boston, MA 02111 (E-mail: nkapur@tuftsmedicalcenter. org).

J Thorac Cardiovasc Surg 2011;142:712-4

0022-5223/ $\$ 36.00$

Copyright $(9) 2011$ Published by Elsevier Inc. on behalf of The American Association for Thoracic Surgery

doi:10.1016/j.jtcvs.2010.11.022
TABLE 1. Laboratory and hemodynamic data

\begin{tabular}{|c|c|c|c|}
\hline Laboratory values & Admission & $\begin{array}{l}\text { Pre- } \\
\text { thrombolysis }\end{array}$ & $\begin{array}{l}\text { Post- } \\
\text { thrombolysi }\end{array}$ \\
\hline Creatinine (mg/dL) & 1.57 & 4.0 & 1.35 \\
\hline Hemoglobin (g/dL) & 14.4 & 10.0 & 11.3 \\
\hline LDH (IU/L) & 244 & 1785 & \\
\hline Plasma-free $\mathrm{Hgb}(\mathrm{mg} / \mathrm{dL})$ & 3.2 & 12.9 & \\
\hline Haptoglobin (mg/dL) & & 3 & \\
\hline Total bilirubin (mg/dL) & 0.8 & 1.2 & 1.0 \\
\hline \multicolumn{4}{|l|}{ Hemodynamics } \\
\hline Right atrial $(\mathrm{mm} \mathrm{Hg})$ & 18 & 20 & 16 \\
\hline $\begin{array}{l}\text { Pulmonary artery } \\
\text { (mean; } \mathrm{mm} \mathrm{Hg})\end{array}$ & $38 / 20(26)$ & $48 / 21(29)$ & $38 / 18(25)$ \\
\hline $\begin{array}{l}\text { Pulmonary } \\
\text { wedge (mm Hg) }\end{array}$ & 18 & 16 & 16 \\
\hline LV (mm Hg) & $\mathrm{n} / \mathrm{a}$ & $95 / 12$ & $38 / 10$ \\
\hline PA saturation & $45 \%$ & $42 \%$ & $64 \%$ \\
\hline Cardiac index $\left(\mathrm{L} / \mathrm{min} / \mathrm{m}^{2}\right)$ & 1.3 & 1.2 & 2.7 \\
\hline
\end{tabular}

noncompliance, and heparin was initiated. An admission echocardiogram revealed a midline septum, intermittently opening aortic valve, and decompressed left ventricle (LV). Right-sided heart catheterization confirmed low cardiac output and elevated filling pressures (Table 1). The patient initially responded well to intravenous milrinone and diuresis.

Six days later, LVAD flow decreased from 4.4 to $2.8 \mathrm{~L} / \mathrm{min}$ without a change in pump speed or blood pressure. Over a 24-hour period, worsening pulmonary congestion, impaired renal function, and hemolysis were observed (Table 1). Logged waveform files suggested an obstructive pattern of reduced flow and increased power requirement. During a gradual increase in pump speed (ramped study), echocardiography demonstrated continuous opening of the aortic valve and no change in LV end-diastolic dimension or septal position (Table 2). Maximizing pump speed did not augment flow despite an increase in power use, and the LV remained dilated, thereby confirming obstruction of pump flow. Echocardiography did not identify an obvious source of obstruction; however, shadowing from the LVAD inflow cannula prevented complete exclusion of an LV thrombus. A non-contrast chest computed tomography scan excluded outflow cannula kinking or aberrant 
TABLE 2. Ramped study

\begin{tabular}{lcccccc}
\hline Speed (rpm) & Flow (L/min) & Power & Aortic valve opening & Mitral regurgitation & Septum & Left ventricular size \\
\hline $\begin{array}{l}\text { Admission } \\
2800\end{array}$ & 4.8 & 4.8 & Intermittent & Mild & Midline & Normal \\
$\begin{array}{l}\text { Ramped speed study } \\
3000\end{array}$ & 3.6 & 5.2 & Continuous & Mild & Right-shift & Dilated \\
3100 & 3.6 & 5.6 & Continuous & Mild & Right-shift & Dilated \\
3200 & 3.8 & 6.1 & Continuous & Mild & Right-shift & Dilated \\
3300 & 3.8 & 6.4 & Continuous & Mild & Right-shift & Dilated \\
3400 & 3.8 & 7.1 & Continuous & Mild & Right-shift & Dilated \\
3500 & 4.1 & 7.8 & Continuous & Mild & Right-shift & Dilated \\
3600 & 4.1 & 8.3 & Continuous & Mild & Right-shift & Dilated \\
Post-thrombolysis & & & Closed & Mild & Left-shift & Decompressed \\
3000 & 4.5 & 4.8 & & & &
\end{tabular}

positioning of the inflow cannula toward the septum or LV free wall.

The patient was referred for intraventricular administration of thrombolytics. The LV was accessed via the right radial artery using a $6 \mathrm{~F}$ pigtail catheter (Figure 1). Baseline hemodynamics demonstrated a normal LV pressure of $93 / 13 \mathrm{~mm} \mathrm{Hg}$. Ventriculography confirmed the absence of flow through the LVAD. Alteplase was administered at a rate of $1 \mathrm{mg} / \mathrm{min}$. After 37 minutes, LV pressure spontaneously reduced to $40 / 8 \mathrm{~mm} \mathrm{Hg}$ and LVAD flow improved to $4.2 \mathrm{~L} / \mathrm{min}$ (Figure 2).

Over a 12-hour period, urine output increased and triggered suction events requiring fluid resuscitation and a reduction in pump speed. Decompression of the LV was confirmed with echocardiography. Three weeks later, the patient underwent successful orthotopic heart transplantation. After explant, the impeller showed no evidence of chronic thrombus.

\section{DISCUSSION}

Device-associated thrombosis is a life-threatening complication of cf-LVAD support. The incidence of device thrombosis in axial-flow LVADs is reported to be 0.02 events per patient year. ${ }^{1}$ The rate of thrombosis with centrifugal cf-LVADs is unknown. The origin of device thrombosis may involve in situ device thrombogenesis or migration of a thrombus into the inflow cannula. Sudden changes in pump parameters are more consistent with ingested thrombus, whereas gradual increases in power and reduced flow suggest in situ thrombogenesis. Subtherapeutic anticoagulation, retained $\mathrm{LV}$ or left atrial thrombus, low pump speeds $(<3.0 \mathrm{~L} / \mathrm{min})$, atrial fibrillation, bacteremia, and preexisting hypercoaguable states may predispose patients to cf-LVAD thrombosis. Management of device thrombosis includes device replacement or thrombolysis. Pump replacement is associated with high morbidity and mortality. ${ }^{2}$ Successful use of a glycoprotein IIB-IIIA inhibitor for the management of cf-LVAD thrombosis ${ }^{5}$ has been reported; however, continuous infusion for 4 days was required for resolution. Management of pump thrombosis with the newer centrifugal cf-LVADs has yet to be reported.

\section{CONCLUSIONS}

Bleeding is a risk of thrombolytic therapy, including intracranial hemorrhage. A potential advantage of
A

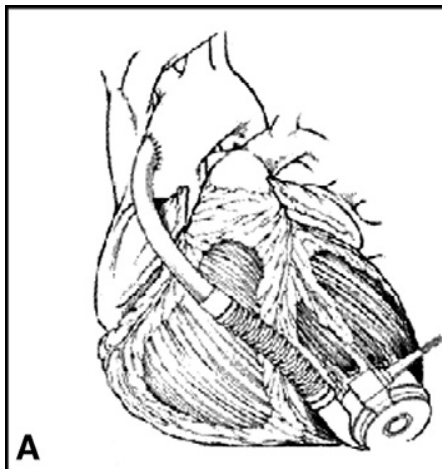

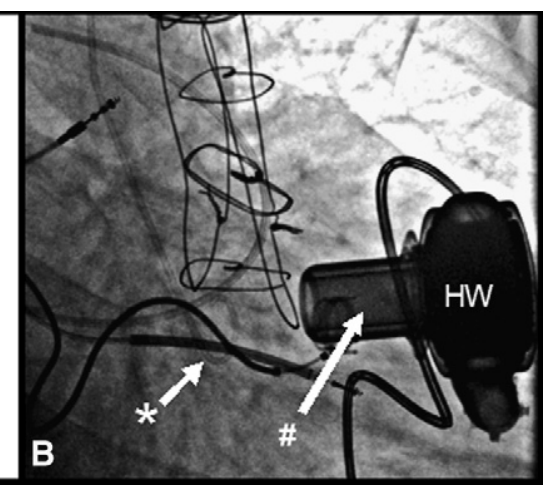

FIGURE 1. A, HeartWare (HeartWare International Inc, Framingham, Mass) LVAD after implantation. B, Right angle oblique plane cineangiographic image showing a $6 \mathrm{~F}$ pigtail catheter $(*)$ in close proximity to the HeartWare LVAD inflow cannula (\#). HW, HeartWare. 


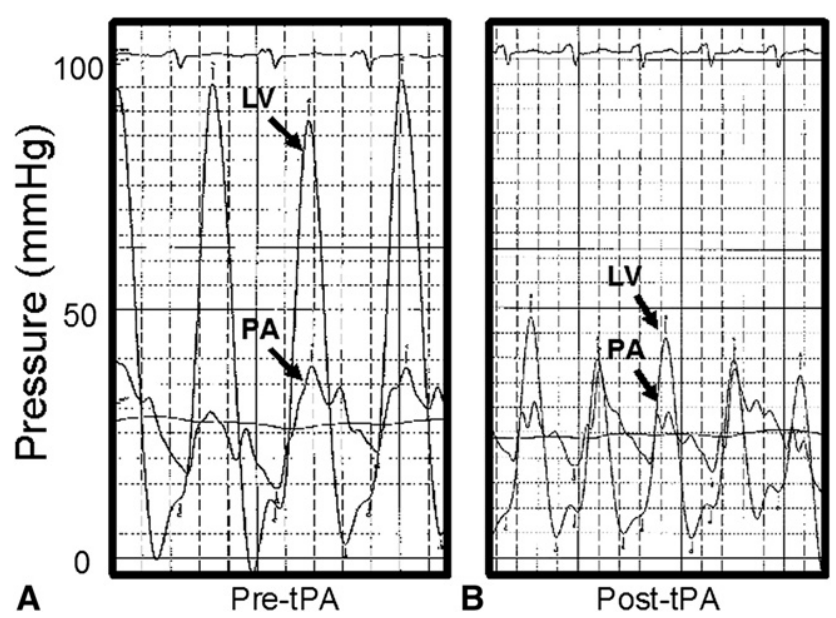

FIGURE 2. Left ventricular $(L V)$ and pulmonary artery $(P A)$ hemodynamic tracings before (A) and after (B) thrombolysis.

intracavitary thrombolysis may be the reduced dose of drug required because of direct application to the LVAD inflow cannula. As nonpulsatile LVADs are increasingly applied in the management of end-stage heart failure, standardization of the percutaneous management of device thrombosis may be necessary.

\section{References}

1. Slaughter MS, Rogers JG, Milano CA, Russell SD, Conte JV, Feldman D, et al. Advanced heart failure treated with continuous-flow left ventricular assist device. N Engl J Med. 2009;361:2241-51.

2. Pagani FD, Miller LW, Russell SD, Aaronson KD, John R, Boyle AJ, et al. Extended mechanical circulatory support with a continuous-flow rotary left ventricular assist device. J Am Coll Cardiol. 2009;54:312-21.

3. Delgado R 3rd, Frazier OH, Myers TJ, Gregoric ID, Robertson K, Shah NA, et al. Direct thrombolytic therapy for intraventricular thrombosis in patients with the Jarvik 2000 left ventricular assist device. J Heart Lung Transplant. 2005;24:231-3.

4. Rothenburger M, Wilhelm MJ, Hammel D, Schmidt C, Tjan TD, Böcker D, et al. Treatment of thrombus formation associated with the MicroMed DeBakey VAD using recombinant tissue plasminogen activator. Circulation. 2002;106(12 Suppl. 1):I189-92.

5. Thomas MD, Wood C, Lovett M, Dembo L, O'Driscoll G. Successful treatment of rotary pump thrombus with the glycoprotein IIb/IIIa inhibitor tirofiban. J Heart Lung Transplant. 2008;27:925-7.

\title{
Video-assisted thoracoscopic surgical tracheobronchoplasty for tracheobronchomalacia
}

\author{
David G. Tse, MD, ${ }^{a}$ Sukgu M. Han, MD, ${ }^{a}$ Burawit Charuworn, MD, ${ }^{\mathrm{b}}$ and Eric S. Kaufer, MD, \\ Los Angeles, Calif
}

The surgical treatment of tracheobronchomalacia has continued to evolve since the operative interventions for tracheomalacia described in 1954 by Nissen. ${ }^{1}$ Recent experience with polypropylene mesh in the management of tracheobronchomalacia has demonstrated satisfactory long-term results. ${ }^{2,3}$ We report 2 cases of video-assisted thoracoscopic surgical tracheobronchoplasty combined

From the Divisions of Thoracic Surgery ${ }^{\mathrm{a}}$ and Pulmonary Medicine, ${ }^{\mathrm{b}}$ Kaiser Permanente Medical Center, Los Angeles, Calif.

Disclosures: Authors have nothing to disclose with regard to commercial support.

Received for publication Sept 21, 2010; revisions received Nov 10, 2010; accepted for publication Nov 23, 2010; available ahead of print Jan 31, 2011.

Address for reprints: David G. Tse, MD, Department of Thoracic Surgery, Kaiser Permanente Medical Center, 6041 Cadillac Ave, Los Angeles, CA 90034 (E-mail: david.g.tse@kp.org).

J Thorac Cardiovasc Surg 2011;142:714-6

$0022-5223 / \$ 36.00$

Copyright (C) 2011 by The American Association for Thoracic Surgery

doi:10.1016/j.jtcvs.2010.11.037 with airway stent placement for the treatment of tracheobronchomalacia.

\section{CLINICAL SUMMARIES \\ Patient 1}

A 56-year-old man with a history of severe chronic obstructive pulmonary disease had undergone 6 hospitalizations for respiratory failure during the previous year. $\mathrm{He}$ reported decreased exercise tolerance and inability to clear airway secretions. Results of pulmonary function tests were suggestive of intrathoracic large airway obstruction. Flexible bronchoscopy demonstrated severe tracheobronchomalacia with collapse of the entire left mainstem bronchus. Dynamic computed tomographic chest scan showed expiratory collapse of the central airways (Figure 1). A right video-assisted thoracoscopic surgical tracheobronchoplasty of the trachea, right mainstem bronchus and bronchus intermedius was performed with polypropylene mesh. The 